\title{
FÓRUM
}

Artigo convidado

Versão original

DOI: http://dx.doi.org/10.159o/So034-759020200602

\section{IMPACTOS DA COVID-19 NAS ORGANIZAÇÕES}

\section{ALESSANDRA DE SÁ MELLO DA COSTA 1}

alessandra.costa@iag.puc-rio.br 0000-0003-3207-2888

\section{ELY LAUREANO PAIVA²}

ely.paiva@fgv.br

oooo-0003-1203-0584

\section{MARCUS VINICIUS PEINADO} GOMES $^{3}$

GomesM@cardiff.ac.uk 0000-0001-5488-249X

\section{VINICIUS ANDRADE BREI ${ }^{4}$}

brei@ufrgs.br

0000-0002-0502-4533

${ }^{1}$ Pontifícia Católica do Rio de Janeiro, Escola de Negócios, Rio de Janeiro, RJ. Brasil

2Fundação Getulio Vargas, Escola de Administração de Empresas de São Paulo, São Paulo, SP, Brasil

${ }^{3}$ Cardiff University, Business School, Cardiff, Reino Unido

${ }^{4}$ Universidade Federal do Rio Grande do Sul, Escola de Administração, Porto Alegre, RS, Brasil
Os desafios para pessoas, organizações e sociedades diante dos impactos da Covid-19 e de uma pandemia global são inúmeros. Como lidar, em nossas práticas cotidianas, com transformações tão imediatas? Como parar para refletir sobre o que fazer diante de demandas tão urgentes? Como construir um sentido coletivo compartilhado e tomar decisões em um momento em que o futuro está em suspenso e o passado não nos ajuda muito com respostas? Acreditamos que, diante desta situação, a possibilidade mais segura é escutarmos o que a ciência tem para nos dizer.

Foi com esse espírito que buscamos mobilizar pesquisadores, avaliadores e editores em torno da tarefa conjunta de construir um número especial que nos indique caminhos possíveis de compreensão do cenário atual e do futuro das organizações. Tarefa árdua: produzir e disseminar conhecimento de qualidade, de maneira simultânea aos acontecimentos e sob o impacto e restrições decorrentes de um necessário isolamento social. No entanto, a resposta foi bastante positiva.

Algumas áreas do conhecimento necessitam de um pouco mais de tempo para a construção de modelos e/ou esquemas analíticos robustos para compreensão dos fenômenos. Outras conseguem contribuir mais de imediato com o avanço do conhecimento ao adaptar pesquisas já em andamento, de modo a jogar luz sobre os novos fenômenos. De qualquer forma, o significativo número de artigos submetidos explicita o esforço e engajamento dos pesquisadores da área de Administração diante dos desafios da pandemia. Desafios para pessoas, organizações e a sociedade.

Na busca de produção acadêmica sobre essas transformações, a chamada da $R A E$ recebeu 165 trabalhos das diversas áreas de conhecimento que compõem o campo acadêmico-científico de Administração de Empresas, dos quais 101 foram encaminhados para o processo de revisão por pares e os demais, rejeitados de imediato. Ao final de um intenso processo de revisão e edição, foram aprovados cinco trabalhos para publicação.

Não foi fácil fazer escolhas, e agradecemos profundamente a todos os pesquisadores que fizeram suas submissões, mas não tiveram os trabalhos aprovados. Esperamos que os pareceres recebidos sirvam para o aprimoramento de seus artigos e que, a partir da reformulação das fragilidades identificadas, eles possam ser publicados no futuro. Agradecemos também a todos os revisores que trabalharam com celeridade, num período de pandemia que afetou a vida de toda a comunidade científica.

Na área de Organizações e Gestão de Pessoas, foram avaliados 33 artigos, que resultaram na aprovação do trabalho de Eduardo Moura, Liliane Furtado e Filipe Sobral, "Epidemia de burnout durante a pandemia de Covid-19: O papel da LMX na redução do burnout dos médicos”, o qual nos mostra a importância da liderança em situações extremas, ao propor que um relacionamento de alta qualidade entre supervisores e médicos pode promover a redução da ocorrência de burnout entre profissionais que estão na linha de frente no tratamento da Covid-19 e seus desdobramentos. 
Na área de Marketing, foram submetidos 14 artigos, quase todos relativos à área de Comportamento do Consumidor. Dentro dessa grande área temática, os artigos abordaram temas como consumo sustentável, desperdício de alimentos, decisões de compra em diferentes canais de marketing, bemestar do consumidor, percepção de risco, intenção de compra e comparação de comportamento de compra entre consumidores de diferentes países. Houve, ainda, algumas poucas submissões de artigos sobre outras subáreas de Marketing, como marcas, marketing digital, e-commerce, disseminação de fake news e mídias sociais. Nenhum artigo submetido abordou aspectos relativos a ensino de marketing.

Os artigos submetidos sobre temas de Marketing foram inicialmente examinados pelos Editores-Convidados, e, após alguns remanejamentos de artigos para outras áreas temáticas e desk-rejections motivadas por contribuições frágeis, sete artigos que abordaram temas de Marketing seguiram para o processo de revisão cega por pares. Esses sete artigos foram avaliados por 14 experientes avaliadores e, em seguida, pelo Editor-Associado Convidado, antes de serem avaliados pela Editora-Chefe. A partir do julgamento conjunto do Corpo Editorial, nenhum dos artigos de Marketing foi aceito para publicação. De modo geral, os dois principais motivos de rejeição dos artigos submetidos foram a falta de contribuição teórica e a fragilidade em aspectos metodológicos nos métodos de pesquisa empregados.

A chamada de artigos era voltada para os impactos da Covid-19 nas organizações, o que, aparentemente, levou os autores a submeterem artigos focados nos aspectos meramente descritivos desses impactos. Sendo a RAE um tradicional periódico científico, o Corpo Editorial tinha a expectativa de que os artigos submetidos apresentassem novas ou inovadoras perspectivas sobre como essa pandemia poderia transformar, modificar ou gerar novas perspectivas teóricas para fenômenos de marketing motivados por essa situação atípica que o mundo vive. Isso não aconteceu. Quase todos os artigos submetidos trouxeram a mera descrição de impactos da Covid-19, sem maiores discussões de implicações teóricas para a área de Marketing. Esse foi o principal motivo apontado pelos pareceristas para rejeição dos artigos. Houve, ainda, outros problemas relativos a aspectos teóricos, como elaboração de hipóteses inconsistentes e propostas de frameworks com fraca sustentação de literatura.

Tão ou mais prevalentes que problemas de superficialidade na contribuição teórica foram os problemas metodológicos, de diversas ordens. 0 mais frequente problema metodológico foi o uso de amostras pequenas, não representativas e coletadas usando o critério de conveniência para seleção dos respondentes. Nos poucos casos de artigos em que houve algum esforço mais relevante de construção teórica, aspectos metodológicos como escalas com problemas de validade e confiabilidade, construtos maldefinidos e amostras com poder estatístico insuficiente para teste de hipóteses impediram que os autores chegassem a conclusões consistentes. Nenhum artigo submetido apresentou abordagens metodológicas inovadoras que pudessem suplantar as fragilidades teóricas e, eventualmente, motivar o aceite do trabalho, o que levou à decisão de não publicação de artigos nessa área.

Na área de Operações, mudanças extremas decorrentes da pandemia de Covid-19 impactaram fortemente organizações de diferentes setores e múltiplas cadeias de suprimentos, exigindo inovações rápidas em produtos e processos. Com base nesse rico contexto de experiências muitas vezes inéditas, foram submetidos 23 artigos que abordaram diferentes temas como inovação tecnológica, resiliência das cadeias de suprimentos e adaptações em operações de serviços.

Os dois artigos selecionados para a edição especial discutem como as organizações responderam às necessidades trazidas pela pandemia com base em inovações e adaptações de seus processos. 0 primeiro artigo, de Anderson Frare e Ilse Maria Beuren, denominado "Efeitos da informação na insegurança e engajamento no trabalho em tempos de pandemia", é uma survey com uma amostra composta por funcionários de uma grande startup financeira brasileira e que, na análise dos dados, utilizou modelagem de equações estruturais. Os resultados sugerem que, durante o período da pandemia, o compartilhamento vertical da informação mitigou questões de insegurança no trabalho, exercendo um efeito positivo no engajamento dos funcionários. O segundo artigo, denominado "Universidade engajada: Resgatando PMEs na crise da Covid-19”, foi elaborado por um grupo de pesquisadores: Daniela Brauner, Fernanda Reichert, Raquel Janissek-Muniz, Aurora Zen, Daniela Callegaro-De-Menezes, Lisiane Closs, Wendy Carraro, Carla Ruppenthal, Fernanda Maria Müller, Marcelo Lubaszewski e Marisa Rhoden. 0 artigo analisa a atuação de uma universidade regional socialmente engajada no apoio de PMEs durante a crise da pandemia. Como resultado, foram identificados os elementos centrais para a promoção do engajamento social: trabalho em equipe, multidisciplinaridade, gerenciamento de projetos, agilidade, alianças, estratégia de comunicação, suporte e reputação da instituição.

$\mathrm{Na}$ área de Organizações, Sustentabilidade e Desigualdades, recebemos 31 manuscritos que abordavam questões relacionada ao meio ambiente, diferentes impactos nas desigualdades e minorias, bem como questões de ensino de Administração como resposta à necessidade de adaptar conteúdos, disciplinas e programas para um formato on-line. Considerando a rapidez com que a pandemia alterou o nosso 
cotidiano em diferentes áreas da academia, incluindo impacto em pesquisa e sobrecarga e excesso de trabalho, receber manuscritos para essa chamada especial é bastante positivo.

Diante desse cenário, 13 manuscritos foram selecionados para revisão. Os trabalhos foram variados, representando a diversidade da própria área. A maioria discutia o impacto da pandemia em muitos aspectos da vulnerabilidade, incluindo questões de gênero e raça, mas também recebemos trabalhos que abordaram o uso de dados pessoais durante a pandemia, sentimentos nas mídias sociais e o desafio que a pandemia trouxe para organizações da sociedade civil. De maneira geral, todos os manuscritos apresentaram uma forte tendência descritiva sobre os impactos da pandemia, sendo essa a razão que não permitiu que muitos avançassem para a publicação.

Dois manuscritos foram aceitos. 0 primeiro dele é "Atuação empresarial para sustentabilidade e resiliência no contexto da Covid-19", em que Mariana Nicolletti, Gabriela Appugliese, Marta Blazek, Paola Fillippi e Luis Bismarchi trazem um olhar sistêmico para a atuação empresarial voltada para a sustentabilidade. O trabalho faz uma análise do ponto de vista da resiliência como uma forma de analisar e compreender o realinhamento das empresas para criação de valor para a sociedade. Por sua vez, Ana Heloísa Lemos, Alane Barbosa e Priscila Monzato, em "Mulheres em home office durante a pandemia da Covid-19 e as configurações do conflito trabalho-família”, examinam como a pandemia impactou o conflito trabalho-família diante da adoção de home office e constatam que, apesar da sobrecarga de trabalho, a adoção não intensificou o conflito trabalho-família para as entrevistadas, inclusive as autoras apontam que a adoção de home office possibilitou uma aproximação das entrevistadas com suas famílias, propiciando, também, mais tempo para atividades físicas e de lazer.

Ainda estamos vivendo a pandemia, e suas consequências continuarão sendo analisadas e discutidas, dos pontos de vista empresarial, social e ambiental. Com certeza, veremos muitos artigos publicados na $R A E$ e em outros periódicos que refletirão, analisarão e teorizarão as mudanças que a pandemia trouxe para as nossas sociedades. Esperamos que o conhecimento que a academia produza e dissemine possa contribuir com mudanças positivas para nossas sociedades, de modo que consigamos enfrentar as desigualdades sociais e impactos ambientais que temos pela frente.

\section{CONTRIBUIÇÃO DOS AUTORES}

Os autores contribuíram de maneira conjunta na redação e revisão final do texto. 